\title{
Obituary on em. o. Univ. Prof. Dr. Hugo Sauer
}

\author{
Michael E. Höllwarth ${ }^{1}$
}

Published online: 11 October 2021

(c) The Author(s), under exclusive licence to Springer-Verlag GmbH Germany, part of Springer Nature 2021

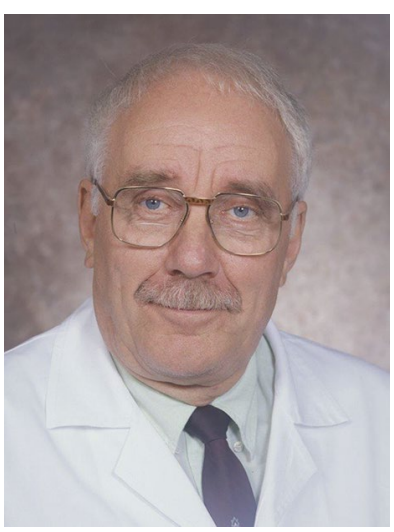

On August 18th this year, Hugo Sauer died in his favorite house in Niederalpl (upper Mürztal) in Styria at the age of 93. The Austrian and also the entire German-speaking pediatric surgical community, thus, mourns a personality that shaped our field for many decades.

Hugo Sauer was born on October 8th 1928 in Graz. At the age of 16 , he was drafted as an air force helper and was taken prisoner by the English at the end of the war in 1945. In the turmoil of this time, he was able to leave the camp with a friend and returned by foot to his parents' home in Graz. After graduating from high school, he completed his medical studies in Graz and was hired as Demonstrator at the Anatomical Institute of the University where he met his beloved wife. After receiving his doctorate in Medicine in 1953, he worked in various Departments until he completed his training as a specialist in surgery in Linz (Director Prof. Fritz Rosenauer) from 1957 to 1963. In 1963, he began as a senior physician at the University Clinic Surgery in Innsbruck (Prof. and Head Paul Huber) and then decided to specialize in Pediatric Surgery with training positions in Linz with Prof. Hermann Hartl, the Nestor of Pediatric Surgery in

Michael E. Hollwarth

michael@hoellwarth.at

1 Medical University of Graz, University Clinic of Pediatric and Adolescent Surgery, Graz, Austria
Austria, and with the famous Prof. Fritz Rehbein in Bremen. From August 1st 1966, he was appointed as Head of the Pediatric Surgical Unit at the University Clinic for General Surgery in Innsbruck, where he also habilitated (Docent) in June 1969 and was appointed as Associate University Professor in 1973.

On January 1st 1975, he was elected as full University Professor of Pediatric Surgery and Head of the Children's Hospital for Surgical and Orthopedical Diseases in Graz, that later became the University Clinic for Pediatric Surgery. This position was very important for his further professional life as Pediatric Surgeon. In April 1975, after my special training period with Prof. Rehbein in Bremen, Sauer offered me the position as a senior physician and his deputy in Graz.

Hugo Sauer was not only an excellent pediatric surgeon, from whom I learned a lot, but above all a person for whom the well-being of the children was an overriding concern. It was typical for him that right at the beginning of his work in Graz he introduced the full-day visiting time of the parents for the children in our Clinic, previously unknown in Graz. The structures, which were very backward in terms of pediatric surgery, were developed by him into a modern Pediatric Surgical Clinic within a few years through the establishment of an intensive care unit with the head Prof. Ronald Kurz, a modern laboratory and the promotion of pediatric radiology by Richard Fotter, later Head of the new Pediatric Radiological Clinic. Soon, he created new facilities for gastro-colointestinal functional studies and an urodynamic lab site, each equipped with the most modern technical facilities at that time. The contact with Pediatricians in private praxis, who had not previously been able to undergo pediatric surgical training, was intensified by so-called regularly sent out "Pediatric Surgical Training Letters".

Since this Pediatric Surgical Clinic was separated by about $7 \mathrm{~km}$ from the University hospital area, his long-term goal was of course to get a new building directly attached to the University Clinic for Pediatrics. I still remember that already in 1975, Hugo Sauer came to me one day and said: "Höllwarth, we have to start right away with the roomand function planning of a new Clinic because in 6 weeks 
from now on the first official activities for the new building will take place". In fact, it took many years more and also required the help of many supporters from the public ( $\mathrm{a}$ community based "brick action" with many public activities to exert pressure on the administration and politicians for a new Clinic building). But probably his tenure as Dean of the Faculty of Medicine (1983-1987) was most important that the new building planning was actually tackled, and we finally moved into the new and excellently equipped Clinic in January 1993. It was perfectly suitable for annually approximately 65,000 outpatients and 5000 surgical procedures in the five operating theaters. In accordance with a new University Organization Law, the Clinic was and is still divided into a Clinical Department of Pediatric Orthopedics and a Clinical Department of General Pediatric Surgery, including Pediatric Traumatology. Sauer had been and remained the head of directors of the entire Pediatric Surgical Clinic.

The care of injured children covered a large part of the outpatients and inpatients workload. Thus, Hugo Sauer soon realized that many injuries could be easily prevented, he founded in 1983, similarly to the Swedish model, the "Austrian Committee for Accident Prevention in Childhood", which became rapidly large national recognition. Pediatric Surgeons of the Clinic started to investigate the circumstances of the most common injuries. Brochures about household and traffic injuries as well as many activities in the public media were important for the success at that time. In 1993, Hugo Sauer handed the responsibility over to me and thanks to the previous success of the Committee further persons could be employed to work full time on these projects and finally a house for injury prevention could be built close to the Clinic for public teaching purposes of children and adults. It is also thanks to Hugo Sauer's tireless initiative and foresight that a modern gait laboratory was set up, primarily dedicated for neuro-orthopedic problems, and one of the most important outpatients' Sports Lab in Austria for children and adolescent was established (under Prof. Peter Schober who, after Prof. Ronald Kurz, headed the pediatric intensive care unit, too). Under Sauer's leadership, numerous young colleagues had been trained as Pediatric Surgeons over the years, some of whom habilitated (Docent) and had been able to take over important management positions in Austria and abroad (Vienna, Klagenfurt, Salzburg, Basel).

One focus of his international work was to make the Pediatric Surgery of Graz known in the wider European area. Above all, the "Southeast European Symposia" and the organization of the first "Three-Country Congress" (for Austrian, German and Swiss Pediatric Surgeons) in Innsbruck in 1978 served this purpose. In addition, Sauer published not only 186 scientific papers in peer reviewed Journals, but also two books ("Checklist for Pediatric Surgery" and "The Injured Child"). After his retirement in 1997, he wrote a very personal and touching book "Kinderschicksale, Mein Leben als Kinderchirurg".

The daily morning and afternoon meetings were the highlights for the now more than 30 members of the medical staff. The leading ward nurses and the leading surgical nurse were also part of these discussions from the very beginning. One thing did not work: if Sauer made a suggestion to try something new and somebody said "that won't work", he could become very upset if you did not at least try to implement the proposal.

Hugo Sauer's successful work not only led to numerous honorary memberships from many European countries, but also to the position as President of the Austrian Society of Pediatric Surgery and also - as a very special recognitionthe position as President of all Austrian Specialties of Surgery. In 2014, Sauer's outstanding activities were honored by the European Society of Pediatric Surgeons (EUPSA) with its highest honor, the Rehbein Medal.

Not only for me, but above all for the "pediatric surgical family" in Graz and abroad, Hugo Sauer will always be remembered in a special way as a formative, dynamic personality, special surgeon and colleague, and above all as a role model who has dedicated his professional life to the children entrusted to him with kindness of heart.

em. o. Univ. Prof. Dr. Michael E. Höllwarth.

Publisher's Note Springer Nature remains neutral with regard to jurisdictional claims in published maps and institutional affiliations. 